\title{
25. Making visible politically masked risks: Inspecting unconventional data visualization of the Southeast Asian haze
}

\author{
Anna Berti Suman
}

\begin{abstract}
This contribution investigates the potential and challenges of data visualization in stimulating a socially and legally accountable governance of environmental risk affecting public health. The visualization analysed results from 'middle-up' mapping efforts of the Southeast Asian haze performed by environmental NGOs and civil society. It is argued that haze governance failures are associated with both a lack of reliable evidence on the haze risk and a denied access to existing information. In response to this informational gap, unconventional solutions to state haze mapping were generated by non-governmental actors. The aim of the chapter is to explore to what extent such counter-mapping succeeded in making visible politically masked risks, triggering human agency at the individual and collective levels, and enabling a more accountable governance of the haze risk.
\end{abstract}

Keywords: Counter-mapping; Environmental risk; Public health; Accountability; Environmental information; Information access.

\section{Introduction}

This contribution investigates the societal response to a pressing environmental risk to public health, the Southeast Asian haze, manifested through data visualization practices. A socio-legal analysis is conducted to understand the implications of haze counter-mapping by non-state actors

Engebretsen, M. and H. Kennedy (eds.), Data Visualization in Society. Amsterdam: Amsterdam University Press, 2020 DOI 10.5117/9789463722902_CH25 
along three lines: firstly, with regard to the filling of informational gaps in haze mapping, making visible 'politically masked' risks; secondly, as a source of social accountability and a trigger for personal and social agency; and thirdly, as a catalyst for legal accountability.

The digital display of the haze phenomenon on online maps appears particularly powerful as it shows the extent of the risk, its rapid movement from one land to another, its volatility but also its origin, shedding light on possible responsibility links. This data visualization therefore communicates complex risk patterns and dynamics in a direct and accessible way. Throughout such dissemination of haze data a process of risk sense-making, learning, and engaging is triggered (see Kennedy \& Engebretsen, this volume). The data visualization at issue has the power to evoke emotions, democratic participation, and other forms of engagement. The emotions awoken are extremely contextual (Kennedy \& Hill, 2017) and intertwine with a pre-existing sense of injustice, distrust, and feelings of anger and insecurity. In line with the approach adopted in this book, the engagement with the haze maps is here understood as layered. In other words, people engaged with the mapping and got engaged by it. Audience responses, identified in the influence on hazeaffected individuals and on haze policymakers, are considered of particular interest. The type of communication inspected is unconventional in the sense of conveying non-institutional and non-institutionalized meaning, being an unexpected and deviating response to dominant patterns of haze risk governance. Eventually, the displayed haze data fill informational gaps and can become influential for decision-making. The social power of data visualizations is inspected in its reactive and transformative potential.

Some of the questions raised by this chapter have been investigated by critical cartography scholars that focused on 'mapping the unmapped' and mapping in situations of crisis. Discussing the accountability potential of counter-mapping, I build on the reflections of Georgiadou et al. (2011) on accountability in the specific context of East Africa; Hohenthal, Minoia and Pellikka (2017) on the potential of critical cartography for co-governing resources; Milan and Gutiérrez (2017) on data activism in Latin America; and my earlier exploratory and more targeted analysis on the subject (Berti Suman, 2017; 2019).

Before answering the key questions of this contribution, the haze phenomenon is contextualized and the response to the haze from relevant institutions and from the local community is described. Subsequently, I discuss the potential and challenges of the haze mapping to fill informational gaps, to foster social accountability, personal and social agency, and legal accountability. In the conclusion, recommendations are sketched on how to release the full potential of this unconventional mapping. Overall, this 
chapter contributes to the still scarce understanding of the social utility and legal admissibility of non-institutional maps.

The methodology that shaped this study is based on a combination between desk research and empirical qualitative research. The empirical research has been deployed through observations performed at Greenpeace International, Legal Unit, Amsterdam, over the period comprised between January and April 2017; web analysis of haze mapping platforms such as Greenpeace's Kepo Hutan and Global Forest Watch Fires; (virtual) participation in topical meetings of Greenpeace Southeast Asia on the haze matter; and targeted communications with stakeholders (e.g. ministries) and organizations (e.g. action groups) involved in the haze issue both in Southeast Asia and elsewhere. In conducting the empirical research, I signed a collaboration agreement with Greenpeace International and have disclosed the research findings to the organization. Nonetheless, the present piece represents exclusively my view and opinion and in no way should be regarded as expressing Greenpeace's position.

\section{The risk at issue: The Southeast Asian Haze}

The Southeast Asian haze is an aggregation in the atmosphere of fine, dispersed, solid or liquid particles or smoke which gives the air an opalescent appearance and may cause harm to human health when inhaled. The haze mostly derives from illegal burning of forests and peatlands. These illegal activities are mainly located in Indonesia and are aimed at preparing land for agricultural use, burning agricultural residue, clearing forest for land acquisition, but they can also be the result of vandalism, accidental ignition, or a mechanism to force inhabitants off the land (Simorangkir, 2007).

The haze is toxic for human health as, during the combustion of forests and peatlands, high amounts of noxious fine particulate matter are released. In addition, the substance is highly volatile, being transported by winds to densely populated areas (Koplitz et al., 2016). Exposure to the haze generates respiratory, heart, and eye-related diseases (Stephen \& Low, 2002) and can hinder the health status of the population in the long term (Quah \& Johnston, 2001).

\section{Digital maps as a response to the haze problem}

The haze challenge has not been properly tackled due to a number of reasons, such as economic and political interests, institutional failures, but also a 
lack of (access to) information. The problem is two-sided: on the one hand, data on fires locations and on the stakeholders responsible are scarce; on the other hand, when the information is available, it is rarely openly accessible to the public (civil society at large). Access to strategic information is here regarded as a crucial 'gatekeeper' that prevents environmental NGOs, local civil society organizations, and individuals from exercising their agency in reacting to the haze. However, when the right to access environmental information is violated, people may find creative ways to get the information they need through unconventional ways, for example making use of mobile technologies and sensors operated by non-state actors.

This non-institutional way of tracking (environmental) risks and displaying them through data visualization can be regarded as 'critical mapping'. Specifically with regard to the Indonesian context, critical mapping practices have been discussed by Peluso (1995), arguably before the data visualization 'hype'. The author inspects the politics of land and forest rights in Kalimantan, its representation in official forest mapping, and the indigenous people's response through 'sketch maps' aimed at reclaiming territories. This chapter builds on this discussion, inserting it in today's reality of massive data visualization. Yet the underlying claims and anger of local people do not differ substantially from the reality described by Peluso. Only the means differ, arguably reinforcing the potential of this critical mapping.

The topic of a tech-enhanced counter-mapping has been discussed by Radjawali, Pye and Flitner (2017), again from a specific Indonesian angle. The authors inspect the use of drones to produce high-quality community controlled maps' aimed at challenging state spatial planning. In the case, the use of drones boosted the demands of the organized (NGOs) and unorganized (the Dayak communities) civil society and facilitated the institutional recognition of the territorial claims. However, the authors also stressed possible adverse social and political consequences of counter-mapping.

This chapter does not argue that such non-institutional mapping can substitute government's action, but rather that it can push policymakers towards action, in addition to providing useful information for the government itself. Such an outcome has been recently illustrated by Gutiérrez (2018) who discusses maps as forms of political counter-power strengthened by data's new potential. The author conceptualizes a 'digital' critical cartography as a 'new paradigm in activism and humanitarianism' through a discussion of two platforms, Ushahidi in Kenya (on the topic see also Bailard et al., 2012) and InfoAmazonia in the Amazon region (the latter platform specifically aimed at tracking environmental issues). 
Throughout the next subsections, the following three aspects of the potential of haze counter-mapping initiatives are investigated: the maps as instruments to fill institutional gaps and make visible politically masked risks; the initiatives as a trigger for social accountability and for personal and social agency; and the data as a source of legal accountability to be possibly used in courts for law enforcement.

\section{Counter-mapping as an instrument to fill institutional gaps}

At the institutional level, governmental actors have engaged in a series of initiatives tackling the haze problem, such as the creation of a haze-targeted Geographical Information System on the Indonesian Jambi province and the launch of a Sub-Regional Haze Monitoring System supported by the Association of Southeast Asian Nations (ASEAN) (see http://haze.asean. org/). In addition, it is worth mentioning the 'One Map initiative' by the Indonesian government, aimed at creating a unified database on Indonesian land use, land tenure, and other spatial data. Despite these efforts, however, most concession maps are not digitalized at present and inter-governmental cooperation against the haze is still weak (Shah, 2016).

In response to these weaknesses, non-governmental actors and civil society have mobilized their energy. In the first group are Indonesian organizations such as 'Walhi' (or Friends of the Earth Indonesia), 'Jatam' (the local Mining Advocacy Network), 'Jakarta Legal Aid' (a local non-profit for legal support), and the Indonesia Centre for Environmental Law. At the international level, the World Resources Institute (WRI) and Greenpeace International together with Greenpeace Southeast Asia intervened. For the second group, the civic response assumed either the form of 'passive' data visualization (accessing maps) or 'active' contribution to visualization (feeding data into existing maps). By launching maps, feeding, or visualizing them, both groups aimed at making visible the 'politically masked' risk posed by the haze (on this concept see Berti Suman, 2018).

Two counter-maps are specifically investigated here, the 'Global Forest Watch Fires Map' and 'Kepo Hutan Map'. Both maps have been launched by international organizations but have generated an actual impact on the countries affected and on the local inhabitants. The choice to focus on these two platforms has been guided by a series of reasons: first, accessibility (I could access both maps remotely and information was available in English although this is only partially true for the Kepo Hutan Map); second, opportunity (I had the opportunity to observe from the Greenpeace International premises the functioning of the platforms, the actors operating them, and the response 
from the local community); third, scope (these mapping initiatives, differently from smaller ones, have a considerable data visualization potential and thus trigger important questions on the effect thereof). Yet, these justifications do not exempt me from acknowledging that my own 'visualization choices' have consequences for the shape of this chapter and that more local initiatives also deserve attention. The focus here on Western-oriented international organizations such as the WRI and Greenpeace is not intended to devalorise the work of local organizations. Future research needs to explore the haze counter-mapping from a local perspective.

The first map, the Global Forest Watch (GFW) Fires was launched by the WRI in 2014 (see Figure 25.1; for GFW maps, see http://fires.globalforestwatch. org/home/, and http://www.wri-indonesia.org/en/resources/maps). The map combines 'real-time satellite data from NASA [...], detailed maps of land cover and concessions [...], weather conditions and air quality data' in order to show fire activity and related effects in the region (Global Forest Watch Fires, n.d.). The platform cooperates with national and local governments, NGOs, corporations, and individuals. The website announces that the map 'offers on-the-fly analysis to show where fires occur' (thus filling institutional gaps) and 'who might be responsible', in order to ensure that 'those who are illegally burning are held accountable' (the legal accountability component) (Global Forest Watch Fires, n.d.). Lastly, the potential for social accountability and personal and social agency References evident in the statement: 'GFW Fires is free to use and follows an open data approach in putting decision-relevant information in the hands of all who want to minimize the impacts of fires [...]' (Global Forest Watch Fires, n.d., emphasis added).

Greenpeace Southeast Asia joined the 'visualization' efforts creating the 'Kepo Hutan' interactive map, produced using open source technology provided by GFW (for Kepo Hutan maps, see http://greenpeace.org/seasia/ id/Global/seasia/Indonesia/Code/Forest-Map/index.html(Indonesian) and http://greenpeace.org/seasia/id/Global/seasia/Indonesia/Code/Forest-Map/ en/index.html (English)). The website affirms that the map is 'a tool to help anyone working on land use [...] and conservation in Indonesia' (personal and social agency) and also 'provides a benchmark for the government's One Map initiative' discussed above (contribution to policymaking) (Greenpeace Southeast Asia, n.d.). The map's 'primary function is to provide greater transparency about who controls areas of land and what happens within it. Previously, this information has not been publicly available to this extent [...]' (Greenpeace Southeast Asia, n.d., emphasis added). From such a statement, the social and legal accountability potential of the initiative emerges. The beneficiaries are both civil society and government bodies. Specific 


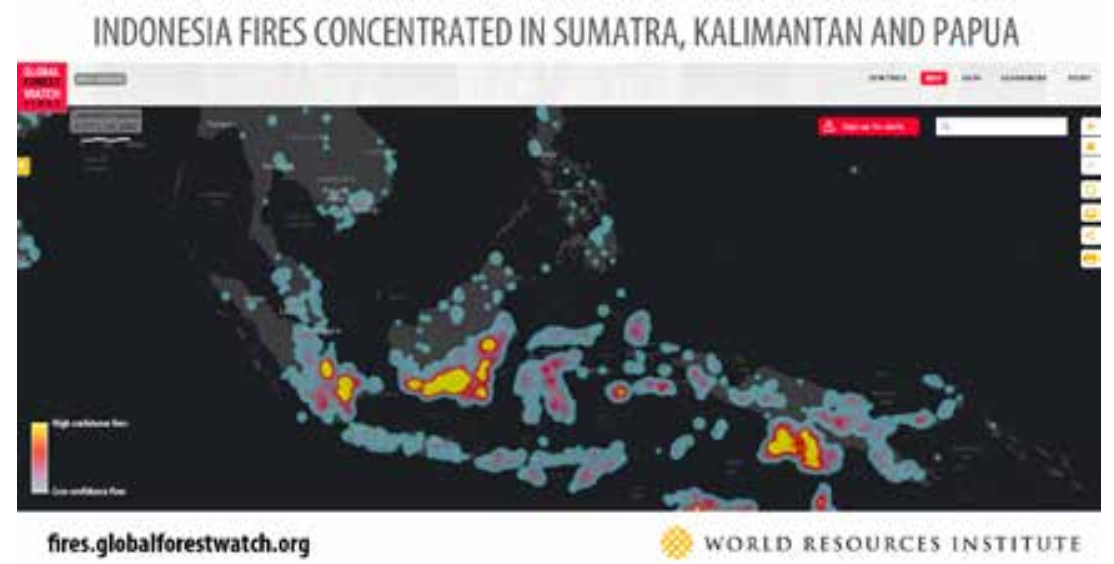

Figure 25.1. The Global Forest Watch Fires Map by the World Resource Institute. From the Global Forest Watch Fires website (https://fires.globalforestwatch.org/). Creative Commons license. Reprinted with permission.

shortcomings of the maps are also acknowledged, such as the diversity of the sources and the obsolete concession data, hindering the digital visualization process. Remarkably, Greenpeace 'invite[s] all stakeholders to help [them] improve [the map]' (Greenpeace Southeast Asia, n.d.). The main obstacle is identified in the government's reluctance to make recent data on concessions 'freely accessible as shapefiles' (Greenpeace Southeast Asia, n.d.), which is an easily analysable format. The website stresses this inaccessibility: '[The] maps presented on this platform are unofficial copies from various sources [...]. Official data are not currently available due to restrictions imposed by the Government of Indonesia' (Greenpeace Southeast Asia, n.d.).

From the combined efforts of Greenpeace and Global Forest Watch Fires, an integrated multilayered platform was generated, based on a vast array of services (e.g. NASA Fire Information System, fire data from the MODIS and VIIRS satellites, and maps from Google Earth) and on a network of infrared sensors capturing heat signatures of fires from the infrared spectral band (see https://fires.globalforestwatch.org/).

The accuracy of fire detection is considered very high: fire data from the MODIS satellite are approximately $1 \mathrm{~km}$ resolution and VIIRS satellite data have a resolution of $375 \mathrm{~m}$, with a very low rate of false positives. In addition, the algorithm used by the maps to detect fires can eliminate sources of false positives and it will send a fire alert only if the system has enough information. Remarkably, the platform can be fed with information gathered by individuals who can upload data from their mobile phones and, in turn, receive information in real time from the platform. 


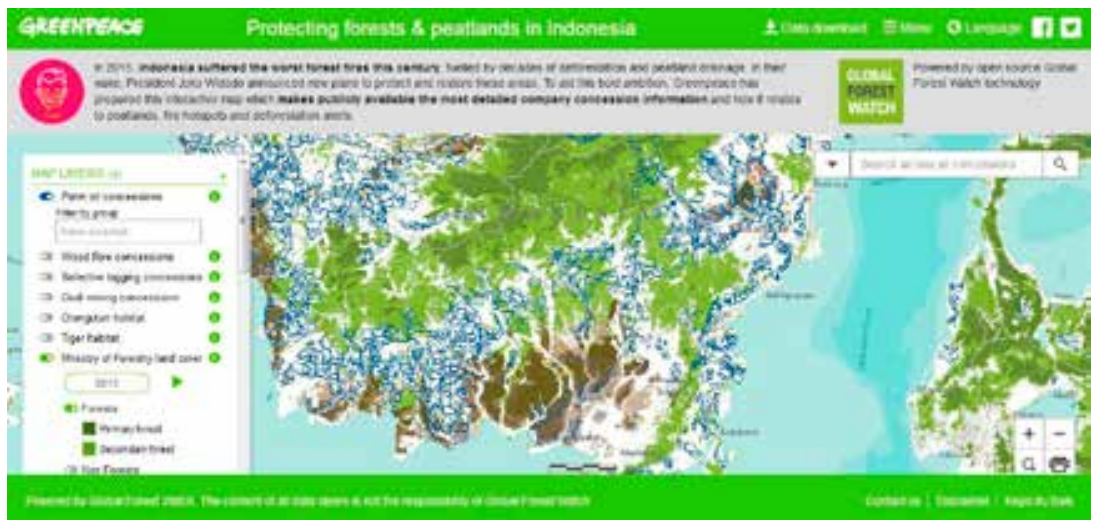

Figure 25.2. Kepo Hutan Map by Greenpeace in collaboration with the World Resource Institute. From Greenpeace Southeast Asia website (http://greenpeace.org/seasia/id/Global/seasia/Indonesia/Code/Forest-Map/en/index.html). Copyright by Greenpeace. Reprinted with permission.

The discussed map system could conceivably fill informational gaps and enhance transparency in haze governance. In addition, it could allow haze-affected people to be alerted about and react to haze events. Eventually, policymakers could also use the system as a tool to understand fire dynamics and plan more informed haze-tackling strategies. Yet non-institutional mapping efforts can contribute to haze policymaking only if they are recognized as valid by state actors.

\section{Non-institutional mapping as a source of social and legal accountability}

\section{Maps as a source of social accountability and human agency}

Individuals exposed to data visualization may experience strong emotional reactions, identified by Kennedy and Hill (2017) as, among others, anger, sadness, and offence. Both maps here inspected can trigger intense feelings as, first, they resonate with haze daily experiences and the related sense of fear, concern, and even injustice. Second, being dynamic and often nearreal-time, they give the observer an understanding of a phenomenon which is often perceived as obscure by the local inhabitants, as information on its causation and extent is rarely accessible.

The maps discussed, although being unconventional in the sense that they deviate from the governmental approach, cannot be considered expressions of the grassroots or 'bottom-up'. Both the WRI and Greenpeace are non-governmental yet institutionalized actors that have a (more or less conflictive) relationship with local governments and hold a specific

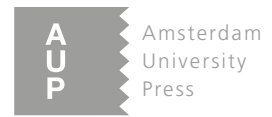


power, which differentiate them from the pure civil society. These maps are initiated by an 'organized' civil society whose organizational structure may shape and orient the counter-mapping agenda. The hope is that such an organizational structure reflects as much as possible the needs, desires, and the expectations of the civil society which the data visualization aims to benefit. This hope seems met as the maps became a platform for the grassroots to gather and communicate haze information. In a sense, these international organizations may be seen as 'middle-up gatekeepers' (as discussed for the case of the Ushahidi crisis mapping by Gutiérrez, 2018). They are intermediary entities which connect the 'bottom' with the 'top' and in some instances are necessary shields for local activists. The truly lay people in the haze discourse would be the individuals who experience risk and who seek/feed information online on a daily basis. Future research should inspect the extent to which the agenda of local organizations and civil society is the same as that of the international organizations involved in haze counter-mapping.

In addition, although the use of the words 'bottom-up' and 'top-down' is dominant in the literature (see, for example, Hai-Ying et al., 2014, p. 1), ongoing discussions suggest that this division may fail to capture the blurred reality of social interactions where the boundaries between the two categories are often confused. Authors discussing participatory environmental governance argue that 'bottom-up' and 'top-down' approaches often coexist (Liu et al.,2014, p. 6) and have the same goals but 'different paths'. Along this line, Rey-Mazón et al. stress that the understanding of the term 'veillance' should go 'beyond mere "sur"- or "sous"-topologies', similarly to what should happen for 'bottom-up' and 'top-down' (2018, p. 24). The dichotomy may require more dynamic terms, reflecting processes of 'closing down' and 'opening up' a field to a narrower or broader number of actors (Stirling, 2008, p. 262). Lastly, these unconventional maps stimulate a discussion on how to categorize them. The options range from countermapping, participatory mapping, grassroots-driven mapping (Dosemagen, Warren \& Wylie, 2011), radical mapping (Denil, 2011), volunteer geographic information (Gutiérrez, this volume), or 'citizen sensing' as argued with regard to noise pollution critical-mapping (Berti Suman, 2018). A combination of counter-mapping, participatory mapping, and citizen sensing may apply.

The preceding discussion suggests that the two maps investigated can be considered external factors to the local context eventually activating a response from the local civil society. Such a response is identified in feelings but also actions. Both feelings and actions configure forms of social 
accountability or 'accountability through engagement' (see, for example, Hughes and Mellado, 2016; Bonner, 2009).

The maps discussed triggered a change in traditional risk mapping, suggesting that not only are public institutions responsible for tracking risks endangering public health, but also non-governmental and civil society actors. With regard to civil society engagement, it should be stressed that the question of who these people are matters. In consideration of uneven access to technology, there is still the fear that individuals in remote areas-often the most exposed to haze pollution-will be excluded from haze countermapping. Rather, well-educated and wealthy activists may be the fulcrum of such initiatives. Future research should tackle this issue by questioning which groups with which interests generate and visualize the data, to which aims, and —importantly—which groups are missing?

Despite the limits of the discussed initiatives, it is worth underlining that the parallel development of (at least) two systems, the institutional and the non-institutional, stimulated a constructive discourse on the appropriateness of the government's approach to the haze. The 'cross-checking' potential of these maps, when state mapping is undermined by a lack of trust, could trigger a social accountability outcome in the sense of multiplying the 'eyes' watching over the government. Although there are clear technical challenges to the success of the unconventional maps, these platforms enabled local actors to gain awareness on the risk they were exposed to and to react to it through adaptation of their personal behaviour and through collective action (the personal and social agency discussed in Poell et al., 2015). Both at the individual and at the collective levels, a transition from passively tracked and profiled individuals and communities to 'active trackers' emerges, configuring a shift from a 'quantified self' to a 'quantified surrounding' of the self (Berti Suman, 2018). The discourse of 'empowering', 'consulting', or 'including' the people in governance processes is arguably replaced by a self-empowerment and auto-inclusion, although through the mediation of pre-existing organizational structures (e.g. Greenpeace). These unconventional mapping initiatives resist top-down imposed means for 'engaging' the people. When communities (more or less supported by organizations) start mapping, they are not 'being consulted', but they actually organize themselves in the first place to carry on their own mapping (see Chambers, 1994, for map-making in rural contexts). They are not only 'data seekers', but actually generate data ('data providers') and become able to exercise their power as concerned stakeholders and as aware societal agents that demand more accountability ('critical map-makers'). Traditional patterns of dominance facilitated by restricted access to strategic information are 
challenged. Technology becomes not only a tool in the hands of corporate and government actors for massive surveillance (Crampton, 2003) but also an opportunity for proactive data activism (Gutiérrez, 2018). A 'reverse' surveillance may even take place as detailed by Radjawali, Pye and Flitner (2017), who showed how community drones have been used to 'watch over' the actions of corporations and the government in areas interdicted to public access.

\section{Maps as a source of legal accountability}

Having reflected on the maps as a source of social accountability and human agency, the focus is now shifted on the possibility that such non-institutional data visualization efforts may 'find their way' to courts. The potential of such maps to provide legally acceptable evidence that could enable civil society to make governors and companies accountable for the haze before judicial bodies is inspected, as a way to bring even further human agency. This analysis resonates with Gutiérrez's (2018) discussion of the evidencegeneration potential of geoweb technologies.

The underlying assumption to this discussion lays in the acknowledgments that these mapping efforts need to be somehow 'institutionalized' to succeed in court. For example, the maps could find legitimization in the Transboundary Haze Pollution Act (THPA) of 2014, aimed at preventing and punishing the causation of transboundary haze pollution. The THPA recognizes the use of digital maps to enforce justice against haze-causing actors. Specifically, Part II-Liability for Transboundary Haze Pollution, Subsection 8-Presumptions, suggests that the haze presumptions can also be based on satellite information. It is made clear that any satellite information applies, thus arguably also including unofficial maps. Part II affirms that ownership/occupation of the land shall be presumed on the basis of maps which can derive from governmental sources but also from any prescribed person through any prescribed means. This very open clause in terms of maps' admissibility leaves room for unconventional haze mapping evidence to be considered valid before courts.

The local academic discussion has devoted attention to the recent developments in the use of electronic evidence in court. For example, Low (2012) discussed Art 116A of the Singaporean Evidence (Amendment) Bill 2012, which states that the Minister of Justice may define a certified process for generating digital evidence from e.g. tracking tools. Pursuant to this provision, the unconventional maps would need to be recognized as resulting from a certified process in order to be used in court. Yet the admission of electronic evidence may also be dependent on the technology involved 
(Seng \& Chakravarthi, 2003), and unconventional maps' validity could be undermined by alleged measuring bias and inaccuracies.

The need to rely on lay-produced maps in haze court proceedings has become pressing due to the reluctance of institutional stakeholders to release official maps, often supported by the judiciary. For example, in February 2017, the Indonesian Administrative High Court ruled in favour of the Environment and Forestry Ministry, judging as lawful the government's decision not to disclose forest and concessions maps, as requested by Greenpeace Indonesia. This ruling clearly opposes a transparent and accountable governance of the haze and was highly criticized by local and international organizations (Jong, 2017). The local environmental organization Walhi was instead successful in having the Indonesian government condemned for negligence in the management of the 2015 haze crisis. The evidence presented during the trial in part derives from the GFW Fires maps, which suggests that unofficial mapping may eventually succeed in court.

\section{Conclusion}

The preceding discussion shows that unconventional data visualization can do 'good' to the affected communities, to the extent that they arise from informational/governance failures. Yet it has been stressed that the reality is more nuanced, as it is unclear how accessible this non-institutional mapping is to the local civil society, and to what extent the agenda of the international organizations behind the maps coincides with that of local actors. Nonetheless, I have argued that it is time to go beyond a polarized 'top versus bottom' debate, as it has been shown that the two layers (and the many more existing layers) often overlap and are blurred. The question of how all these actors and levels of governance differently relate to the challenge of making haze data open to the public has been partially discussed in this chapter but deserves further attention in future research. The relation between data accessibility and the legal framework of different countries, enabling or hindering use of counter-mapping in court, should also be inspected in future research. The extent to which these critical maps can be considered valid (or 'just good enough'; Gabrys, Pritchard, \& Barratt, 2016) to show correlations between concessions' ownership, illegal fires, and haze events should also be further analysed.

Despite the need for future research, this discussion contributes to the ongoing debate on the need for more transparent and accountable haze 
governance in Southeast Asia. It has been demonstrated that unconventional mapping efforts can effectively track and visualize the haze. In addition, they can be a tool enabling local dwellers to react to haze events. Furthermore, such instruments bring the promise to fill gaps generated by institutional failures and make visible politically masked risks. Moreover, their potential to stimulate personal and social agency has been stressed. The rise of a 'cross-checking' mechanism has been identified as a potential source of social accountability. Lastly, even the possibility of a legal accountability outcome has been advanced.

Considering the outlined opportunities and challenges, the following recommendations can be made for the release of the maps' full potential:

- These initiatives should respond to informational/governance failures, which justify the need for an additional system;

- The organizational structure behind these mapping initiatives should reflect as much as possible the needs, desires, and expectations of the civil society for whose benefit the data visualization is aimed, in order not to undermine the social accountability and human agency potential;

- To be a source of legal accountability, the maps should be recognized as valid by state actors, for example through 'certification' mechanisms (which, however, may compromise their non-institutional nature);

- Measuring bias and inaccuracies have to be addressed in order to facilitate their admissibility before courts.

The present reflections and recommendations could guide organizations and civil society actors in developing (haze) data visualization initiatives in a way that ensures their effectiveness and impact, while preserving their non-institutional nature and potential for human agency.

\section{References}

Bailard, C., Baker, R., Hindman, M., Livingston, S., \& Meier, P. (2012). Mapping the maps: A meta-level analysis of Ushahidi and Crowdmap. Washington: Crowdglobe.

Berti Suman, A. (2017). Towards a map-based accountability for environmental health risk? The case of the Equatorial Asian Haze. Proceedings of the 13th International Conference on Internet, Law \& Politics, Managing Risk In the Digital Society. ISBN: 978-84-697-4474-1.

Berti Suman, A. (2018). Challenging risk governance patterns through citizen sensing: the Schiphol Airport case. International Review of Law, Computers \& Technology, 32(1), 155-173. http://doi.org/10.108o/1360o869.2018.1429186 
Berti Suman, A. (2019). The role of information in multilateral governance of environmental health risk: lessons from the Equatorial Asian Haze case". Journal of Risk Research - Special Issue on 'Multilateral Governance of Technological Risk'. https://doi.org/10.1080/13669877.2019.1617338

Bonner, M. D. (2009). Media as social accountability: The case of police violence in Argentina. International Journal of Press/Politics, 14(3), 296-312.

Chambers, R. (1994). Participatory Rural Appraisal (PRA): Analysis of experience. World Development, 22(9), 1253-1268.

Crampton, J. W. (2003). Cartographic rationality and the politics of geosurveillance and security. Cartography and Geographic Information Science, 3o(2), 135-148.

Denil, M. (2011). The search for a radical cartography. Cartographic Perspectives, 68, 7-28. http://doi.org/o.14714/CP68.6

Dosemagen, S., Warren, J., \& Wylie, S. (2011). Grassroots mapping: Creating a participatory map-making process centered on discourse. Journal of Aesthetics and Protest (8). Retrieved March 9, 2018 from https://www.joaap.org/issue8/ GrassrootsMapping.htm.

Gabrys, J., Pritchard, H., and Barratt, B. (2016). Just good enough data: Figuring data citizenships through air pollution sensing and data stories. Big Data \& Society, 3(2). http://doi.org/10.1177/2053951716679677

Georgiadou, Y., Baba, B., Becht, R., Hoppe, R., Ikingura, J., Kraak, M.-J., Lance, K., ... Verplanke, J. (2011). Sensors, empowerment, and accountability: A Digital Earth view from East Africa. International Journal of Digital Earth, 4(4), 285-304. https://doi.org/10.1080/17538947.2011.585184

Global Forest Watch Fires. (n.d.). About. Retrieved November 28, 2018 from https:// fires.globalforestwatch.org/about/

Greenpeace Southeast Asia. (n.d.). Protecting forests \& peatlands in Indonesia. Retrieved November 28, 2018 from https:/greenpeace.org/seasia/id/Global/ seasia/Indonesia/Code/Forest-Map/en/about.html

Gutiérrez, M. (2018). Maputopias: Cartographies of knowledge, communication and action in the big data society - The cases of Ushahidi and InfoAmazonia. GeoJournal, 1-20. http://doi.org/10.1007/s10708-018-9853-8

Hai-Ying, L., Kobernus, M., Broday, D.M., \& Bartonova, A. (2014). A conceptual approach to a citizens' observatory: Supporting community-based environmental governance. Environmental Health, 13. http://doi.org/10.1186/1476-069X-13-107

Hohenthal, M., Minoia, P., \& Pellikka, P. (2017). Mapping meaning: Critical cartographies for participatory water management in Taita Hills, Kenya. The Professional Geographer, 69(3), 383-395. http://doi.org/10.1177/1940161215614565.

Hughes, S., \& Mellado, C. (2016). Protest and accountability without the press: The press, politicians, and civil society in Chile. The International Journal of Press/ Politics, 21(1), 48-67. 
Jong, H.N. (2017, February 16). Forest cover maps to remain confidential: Court. The Jakarta Post. Retrieved from http://www.thejakartapost.com/news/2017/02/16/ forest-cover-maps-to-remain-confidential-court.html

Kennedy, H., \& Hill, R. L. (2017). The feeling of numbers: Emotions in everyday engagements with data and their visualisation. Sociology, 52(4), 830-848. https:// doi.org/10.1177/0038038516674675.

Koplitz, S. N., Mickley, L. J., Marlier, M. E., Buonocore, J. J., Kim, P. S., Liu, T., Sulprizio, M. P., DeFries, R. S., Jacob, D. J., Schwartz, J. (2016). Public health impacts of the severe haze in Equatorial Asia in September-October 2015: Demonstration of a new framework for informing fire management strategies to reduce downwind smoke exposure. Environmental Research Letter, 11. http://doi.org/10.1088/17489326/11/9/094023

Liu, H. Y., Kobernus, M., Broday, D. M., \& Bartonova, A. (2014). A conceptual approach to a citizens' observatory - supporting community-based environmental governance. Environmental Health, (13), 107. http://doi.org/10.1186/1476-o69X-13-107

Low, W. (2012). A Commentary on the Amendments to the Electronic Evidence Provisions in the Singapore Evidence Act. Singapore Law Gazette 191, 11-23.

Milan, S., \& Gutiérrez, M. (2017). Technopolitics in the age of big data: The rise of proactive data activism in Latin America. In: F. Sierra Caballero \& T. Gravante (Eds.), Networks, movements and technopolitics in Latin America: Critical analysis and current challenges. (pp. 95-109). London: Palgrave

Peluso, N. L. (1995). Whose woods are these? Counter-mapping forest territories in Kalimantan, Indonesia. Antipode, 27(4). http://doi.org/10.1111/j.1467-8330.1995. tboo286.x.

Poell, T., Kennedy, H., \& van Dijck, J. (2015, December 7). Special theme: Data \& agency [Blog post]. Retrieved from http://bigdatasoc.blogspot.com.es/2015/12/ special-theme-data-agency.html.

Quah, E., \& Johnston, D. (2001). Forest fires and environmental haze in Southeast Asia: Using the 'stakeholder' approach to assign costs and responsibilities. Journal of Environmental Management, 63, 181-191.

Radjawali, I., Pye, O., \& Flitner, M. (2017). Recognition through reconnaissance? Using drones for counter-mapping in Indonesia. The Journal of Peasant Studies, 44(4), 817-833. http://doi.org/10.1080/03066150.2016.1264937

Rey-Mazón, P., Keysar, H., Dosemagen, S., D’Ignazio, C., \& Blair, D. (2018). Public lab: Community-based approaches to urban and environmental health and justice. Science and Engineering Ethics, 24(3), 971-997. http://doi.org/10.1007/s11948-018-0059-8

Seng, D., \& Chakravarthi, S. (2003). Computer output as evidence: Final report. Singapore: Technology Law Development Group, Singapore Academy of Law. Retrieved April 10, 2018 from https://www.sal.org.sg/Portals/o/PDF\%2oFiles/Law\%20 Reform/TLDG-2003-09\%20-\%2oComputer\%2oOutput\%20as\%2oEvidence.pdf 
Shah, V. (2016). New map launched on company concessions in Indonesia. Press release of 22 March 2016. Ecobusiness. Retrieved February 14, 2018. http://www.ecobusiness.com/news/new-map-launched-on-company-concessions-in-indonesia/

Simorangkir, D. (2007). Fire use: Is it really the cheaper land preparation method for large-scale plantations? Mitigation and Adaptation Strategies for Global Change, 12, 147-164.

Stephen, A., \& Low, L. G. (2002). Impact of haze on health, mortality and mitigation programme. World Conference on Land and Forest Fire Hazards 2002, Kuala Lumpur, 319-323.

Stirling, A. (2008). 'Opening Up' and 'Closing Down': Power, participation, and pluralism in the social appraisal of technology. Science, Technology, \& Human Values, 33(2), 262-294. http://doi.org/10.1177/0162243907311265

\section{About the author}

Anna Berti Suman is a PhD researcher at the Tilburg Institute for Law, Technology, and Society. Her PhD project aims at investigating the influence of 'Citizen Sensing' practices on environmental risk governance. She has work and research experience in environmental health and technology, environmental law, and community engagement in environmental decision-making. 